\title{
ANÁlisis de COSTOS DEL SECTOR PORTUARIO ${ }^{1}$
}

María Alicia Schmidt ${ }^{2}$

\section{Introducción}

El sector portuario de la región sudoeste bonaerense es un área de gran concentración para la actividad económica en la cual se interrelacionan actividades primarias, industriales y de servicios, generando un efecto multiplicador sobre la economía regional. Su función básica es actuar como nexo o enlace entre los nodos de transporte marítimo y terrestre. La ubicación geográfica y las características propias del Puerto de Bahía Blanca (en adelante PBB) lo hacen un punto neurálgico de confluencia comercial y vinculación estratégica. Este sistema portuario brinda una amplia variedad de servicios y alternativas de operaciones, con la ventaja de poseer una salida directa al océano Atlántico. Es el único puerto de aguas profundas del país y está especialmente preparado para las operaciones de tráfico con buques supergraneleros y grandes buques tanque. La jurisdicción de actuación portuaria comprende diversas zonas de operaciones, i.e., Puerto de Ingeniero White; Puerto Galván; Puerto de Rosales y Base Naval Puerto Belgrano (solo actividad militar).

Este trabajo tuvo como objetivo realizar un análisis de costos del servicio de practicaje naval brindado por empresas del sector, como servicio conexo a la navegación. Esto se fundamenta en la necesidad de las empresas en conocer sus costos desde una óptica de gestión como herramienta para plantear estrategias y tomar decisiones. Este servicio integra el Tarifario Total de Servicios y

1 Resumen del trabajo final para la especialización en Costos y Gestión Empresarial (UNS), aprobado el 7/12/2017, tutor: Enrique N. Cartier.

2 Universidad Nacional del Sur, Departamento de Ciencias de la Administración (UNS-DCA). Email: alicia.schmidt@uns.edu.ar 
Tasas que son aplicables al buque y a la carga al transitar por la vía marítima del PBB, por lo tanto se plantea la necesidad de determinar el tarifario total de servicios y tasas para conocer el costo que soportará una empresa naviera o fletador por transitar y operar en el estuario de Bahía Blanca. Es importante aclarar que el estudio fue realizado abarcando el rango temporal enero-diciembre de 2016. En el cuerpo del documento completo se exponen aspectos teóricos y metodológicos que sustentan el estudio realizado.

\section{Estructura y contenido}

El trabajo realizado está dividido en dos secciones diferentes: (a) el análisis del costo de la empresa de servicios conexos a la navegación "Practicaje Naval", (b) confección del cuadro tarifario completo con las tasas y servicios aplicables al buque y a las cargas movilizadas en jurisdicción del PBB.

En el desarrollo de la sección (a) se describen aquellos servicios conexos o de apoyo a la navegación, i.e., practicaje, remolque y amarre, participantes de la operatoria portuaria de movilización de buques.

Seguidamente se expone detalladamente el Mapa del Proceso Productivo de la empresa objeto de estudio, explicando sus características y particularidades. En dicho mapeo se determina la prestación de los servicios, identificando los elementos de mayor relevancia a la luz de la teoría general del costo. A continuación, se presenta un resumen del mapeo:

- Factores productivos: aquellos insumos necesarios - necesariedad del factor - para la prestación de los servicios, i. e., bienes consumibles con el primer uso, bienes de capital, servicios intermedios y recursos humanos.

- Acciones inmediatas: aquellas donde el servicio es consumido por el producto final, en este caso, la prestación del servicio propiamente dicho. Para el servicio de practicaje las acciones más significativas son las de “Disposición del Práctico", “Trasbordo del Práctico" y “Asesoramiento y Conducción del Práctico".

- Acciones mediatas: generan servicios que son consumidos por otras acciones (mediatas o inmediatas). Se encuentra a la "Administración" siendo el soporte de las operaciones realizadas y brindando servicios de apoyo a las acciones inmediatas.

- Resultados productivos - objetos de costos: conforman los servicios ofrecidos: 
Servicios de practicaje: el tipo de operación/tráfico que realice el buque al ingresar al canal y el tamaño del mismo constituyen las variables condicionantes de agrupamiento de los mismos (esta información fue segmentada y agrupada).

Finalmente, la sección (a) culmina con la realización del análisis de costo el cual fue construido a partir de la aplicación del análisis marginal.

Por otra parte, la sección (b) presenta un estudio del costo de movilización de carga vía marítima mediante la ruta del estuario local del Puerto de Bahía Blanca, desde una visión integradora y completa de los diferentes tarifarios intervinientes según la tipología de operación y de tráfico. A partir de ello, se analiza el impacto que manifiesta el servicio brindado de practicaje naval en la totalidad del tarifario aplicado a buques que ingresan al canal para operar o solo alistarse. Esto permite examinar y ponderar la incidencia de los múltiples rubros y agentes en los costos asociados al PBB y determinar estrategias tarifarias más competitivas.

\section{Consideraciones finales}

En último lugar, se manifiestan las consideraciones finales y las posibles líneas futuras de investigación. El documento analiza y determina el impacto de los servicios conexos a la navegación en el esquema completo del tarifario total aplicable a los buques y a la carga movilizada a través del PBB. Esta información es de significativa relevancia dado que en un futuro próximo es posible la ocurrencia de un cambio en la estructura del tráfico operacional del PBB, incrementando la cantidad de buques y toneladas movilizadas en puerto. La causa responde a diferentes situaciones tales, e. g., la instalación de un parque eólico en cercanías de la ciudad de Bahía Blanca, la reapertura del comercio exterior a través de importaciones y la derogación de los reembolsos patagónicos, entre otros. Tales sucesos deben alertar a las empresas del sector portuario y planificar el potencial incremento en la operatoria diaria portuaria.

En conclusión, el conocimiento completo del esquema de tarifas aplicable en la jurisdicción es de significativa utilidad al momento de planificar estrategias que contribuyan a la competitividad de los servicios portuarios respecto de otros puertos de la región y para corregir las distorsiones que puede producir la existencia de determinados subsidios sobre los servicios. 


\section{Futuras líneas de investigación}

Finalmente, el documento contempla futuras líneas de trabajo atendiendo a la necesidad de contar con información útil y oportuna en un contexto dinámico reconfiguración creciente, i. e.:

a. Realización de un análisis interportuario de tarifarios comparativos y sugerencia de acciones para incrementar la competitividad.

b. Determinación de costos de la estructura productiva de los muelles más importantes, estos son: Posta de Inflamables, Muelle Multipropósito (portacontenedores), y Muelle Ministro Carranza.

c. Análisis del tarifario portuario aplicado al buque regasificador y el costo que genera para el puerto el desarrollo de esta operatoria, considerando asimismo los eventuales riesgos y el impacto ambiental producido. A la fecha de presentación de esta reseña, este punto se encuentra suspendido.

(C) 2017 por los autores; licencia otorgada a la revista Escritos Contables y de Administración. Este artículo es de acceso abierto y distribuido bajo los términos y condiciones de una licencia Atribución-No Comercial 4.0 Internacional (CC BY-NC 4.0) de Creative Commons. Para ver una copia de esta licencia, visite https://creativecommons.org/licenses/by-nc/4.0/ 